alone and that zinc should be given to patients who do not respond to cupriuretic treatment.

We thank Professor A Staal and Dr O J A Th Meuwissen for referring the patients, and Professor J Van Gijn and Dr J A VeigaPires for their helpful comments on the report.

\section{References \\ ' Sass-Kortsak A, Bearn AG. Hereditary disorders of copper metabolism. In Stanbury JB, Wyngaarden JB, Fredrickson DS, eds. The metabolic basis of \\ alshe JM. Penicillamine, a new oral therapy for Wilson's disease. Am f Med \\ $1956 ; 21: 487-95$. \\ Walshe JM. Penicillamine and the SLE syndrome. $\mathcal{F}$ Rheumatol $1981 ; 8$, suppl 7 \\ 'Walshe JM. Wilson's disease (hepatolenticular degeneration). In: Vinken PJ, Bruyn GW, Klawans HL, eds. Handbook of clinical neurology. Vol 27. Metabolic and deficiency diseases of the nervous system. Part I. Amsterdam: North Holland Publishing Company, 1976:379-414 \\ Walshe JM. Treatment of Wilson's disease with trientine (triethylene tetramine) \\ dihydrochloride. Lancet 1982;i:643-7.
Tschumi P, Floersheim GL. Zur Verträglichkeit von hochdosiertem peroralem Zinksulfat. Schweiz Med Wochenschr 1981;111:1573-7. \\ Schouwink G. De hepato-cerebrale degeneratie (met een onderzoek naar de zinkstofwisseling). Amsterdam: University of Amsterdam, 1961. Thesis. \\ Hoogenraad TU, Koevoet R, de Ruyter Korver EGWM. Oral zinc sulphate as long term treatment in}

Hoogenraad TU, Van den Hamer CJA, Koevoet R, de Ruyter Korver EGWM. Oral zinc in Wilson's disease. Lancet 1978; ii:1262.

${ }^{\circ}$ Hoogenraad TU. De behandeling van koperstapeling met oraal zink. In: Van den Berg SG, Kater A, Soeters PB, eds. Lever en galwegen 1981. Utrecht/Antwerp: Bohn, Scheltema, and Holkema, 1981 :87-91.

therapy in 4 patients

12 Nooijen JL, Van den Hamer CJA, Houtman JPW, Schalm SW. Possible errors in sampling percutaneous liver biopsies for determination of trace clement status : applicatic $335-8$.

13 Van den Hamer CJA, Janssens AR, Hoogenraad TU. Onderzoek van de koperstofwisseling met ${ }^{64} \mathrm{Cu}$. Nucleair Geneeskundig Bulletin 1981;3:71-80.

' Longe AC, Glew RH, Omene JA. Wilson's disease, report of a case in a Nigerian. Arch Neurol 1982;39:129-30.

${ }^{15}$ Mills CF. Metabolic interactions of copper with other trace elements. In: Biological roles of copper. Amsterdam: Excerpta Medica, 1980:49-69. (Ciba Foundation
Symposium No 79.)

${ }^{16}$ Prasad AS, Brewer GJ, Schoomaker EB, Rabbani P. Hypocupremia induced by zinc therapy in adults. $\mathcal{f} A M A 1978 ; 240: 2166-8$.

17 Pfeiffer CC, Papaioannou R, Rohler A. Effect of chronic zinc intoxication on copper levels, blood formation and polyamines. Fournal of Orthomolecular copper levels, blood form
Psychiatry 1980;9:79-89.

${ }^{8}$ Herpin T. Du pronostic et du traitement de l'épilepsie. Paris: Baillière, 1852.

19 Wulf HR. Rational diagnosis and treatment. Oxford: Blackwell Scientific Publications, 1976.

${ }^{20}$ Lasagna L. Historical controls; the practitioner's clinical trials. N Engl f Med

"Brewer GJ, Hill GM, Prasad AS, Cossack ZT, Rabbani P. Oral zinc therapy for

${ }^{22}$ Van den Hamer CJA, Hoogenraad TU. ${ }^{64} \mathrm{Cu}$-loading tests for monitoring zinc therapy in Wilson's disease. Trace Elements in Medicine (in press).

(Accepted 9 April 1984)

\title{
Observations on the mechanism of hypoxaemia in acute minor pulmonary embolism
}

\begin{abstract}
An automated computer analysis of ventilation-perfusion lung scans was used to derive graphical data from lung scans of 11 patients with acute minor pulmonary embolism, free of pre-existing cardiorespiratory disease, and with no evidence of intrapulmonary complication or pleural effusion. In each case the analysis showed the presence of areas of lung, remote from those affected by the pulmonary embolism, that had a pathological disturbance of ventilation-perfusion matching with relative overperfusion. Such a disturbance would cause hypoxaemia. When the extent of the mismatching was calculated in terms of relative blood flow and alveolar ventilation it correlated well with the degree of arterial hypoxaemia.
\end{abstract}

It is proposed that in acute minor pulmonary embolism the development of ventilation-perfusion mismatching in areas of lung unaffected by the embolic event may be an important mechanism of hypoxaemia.

\section{Introduction}

Acute pulmonary embolism is usually accompanied by hypoxaemia. ${ }^{1-3}$ There is no obvious reason, however, why an area of reduced perfusion should result in blood traversing the

Charing Cross Hospital, London W6 8RF

G H BURTON, BSC, MRCP, registrar, department of medicine

W A SEED, PHD, FRCP, reader in medicine

P VERNON, MSC, principal physicist, department of nuclear medicine

Correspondence to: Dr W A Seed. lungs without being oxygenated, and despite several hypotheses the mechanism remains unresolved. We have developed an automated computer analysis of ventilation-perfusion lung scans that permits quantitative estimation of the distributions of ventilation and perfusion in the lungs. We used this to look for possible pathophysiological mechanisms for the hypoxaemia observed with acute minor pulmonary embolism.

\section{Patients and methods}

PATIENT SELECTION

We examined the case notes of several hundred patients whose diagnosis at discharge from this hospital from January 1975 to August 1982 had included pulmonary embolism. Criteria for inclusion in the study were: (1) A firm clinical diagnosis of acute minor pulmonary embolism. This was defined as the sudden onset of dyspnoea-with or without cough, haemoptysis, or pleuritic chest pain-that could not be accounted for by any other mechanism on clinical and chest $x$ ray examination. (2) No known pre-existing cardiovascular or respiratory disease. (3) A predisposing factor to the development of thromboembolic disease. (4) The presence on examination of tachypnoea and tachycardia. (5) A ventilation-perfusion lung scan taken within seven days after the acute event that was independently reported as supporting the diagnosis of acute minor pulmonary embolism. (6) Arterial blood gas tensions obtained within 24 hours of the lung scan and with the patient breathing room air. (7) A chest $x$ ray film taken within 24 hours of the lung scan that showed no intrathoracic radiological abnormality.

Only 11 cases satisfied all these criteria. Table I gives further details of these cases.

\section{VENTILATION-PERFUSION LUNG SCAN}

Lung scans were performed using krypton- $81 \mathrm{~m}$ for ventilation and technetium- $99 \mathrm{~m}$ macroaggregated albumin for perfusion. Details of the method of computer analysis have been reported elsewhere. ${ }^{4-6}$ 
TABLE I-Clinical characteristics of 11 patients with acute minor pulmonary embolism (clinical observations made at time of acute event)

\begin{tabular}{|c|c|c|c|c|c|c|c|c|c|c|c|}
\hline $\begin{array}{l}\text { Case } \\
\text { No }\end{array}$ & $\underset{\text { (years) }}{\text { Age }}$ & Sex & $\begin{array}{l}\text { Smoking } \\
\text { history } \\
\text { (pack } \\
\text { years*) }\end{array}$ & Predisposing factor & $\begin{array}{l}\text { Respiratory } \\
\text { rate } \\
\text { (breaths/min) }\end{array}$ & $\begin{array}{c}\text { Pulse } \\
\text { (beats/min) }\end{array}$ & $\begin{array}{l}\text { Blood } \\
\text { pressure } \\
(\mathrm{mm} \mathrm{Hg})\end{array}$ & $\begin{array}{l}\text { Jugular } \\
\text { venous } \\
\text { pressure } \\
(\mathrm{cm})\end{array}$ & $\begin{array}{l}\text { Pleural } \\
\text { rub }\end{array}$ & $\begin{array}{l}\text { Chest } \\
x \text { ray } \\
\text { findings }\end{array}$ & Other findings \\
\hline 1 & 27 & $\mathrm{~F}$ & 0 & 5 days postoperatively & 30 & 140 & $130 / 80$ & 0 & - & Normal & Pulmonary angiography positive; tender \\
\hline $\begin{array}{l}2 \\
3\end{array}$ & $\begin{array}{l}65 \\
58\end{array}$ & $\underset{F}{F}$ & $\begin{array}{l}0 \\
0\end{array}$ & $\begin{array}{l}6 \text { days postoperatively } \\
\text { Previous deep vein } \\
\text { thrombosis }\end{array}$ & $\begin{array}{l}\text { Raised } \\
\text { Raised }\end{array}$ & $\begin{array}{l}120 \\
100\end{array}$ & $\begin{array}{l}110 / 70 \\
120 / 90\end{array}$ & $\begin{array}{r}0 \\
+2\end{array}$ & 二 & $\begin{array}{l}\text { Normal } \\
\text { Normal }\end{array}$ & $\begin{array}{l}\text { Leg phlebography positive } \\
\text { Leg phlebography positive }\end{array}$ \\
\hline $\begin{array}{l}4 \\
5\end{array}$ & $\begin{array}{l}70 \\
84\end{array}$ & $\begin{array}{l}\mathrm{F} \\
\mathrm{M}\end{array}$ & $\begin{array}{l}0 \\
0\end{array}$ & $\begin{array}{l}2 \text { weeks' bed rest } \\
\text { Carcinoma of bladder }\end{array}$ & $\stackrel{25}{25}$ & $\begin{array}{r}90 \\
100\end{array}$ & $\begin{array}{l}140 / 75 \\
110 / 70\end{array}$ & $\begin{array}{l}0 \\
0\end{array}$ & $\overline{+}$ & $\begin{array}{c}\text { Normal } \\
\text { Over- } \\
\text { inflated } \\
\text { lung } \\
\text { fields }\end{array}$ & Lung function tests normal 6 weeks later \\
\hline $\begin{array}{l}6 \\
7\end{array}$ & $\begin{array}{l}59 \\
30\end{array}$ & $\begin{array}{l}\mathbf{M} \\
\mathbf{M}\end{array}$ & $\begin{array}{l}8 \\
5\end{array}$ & $\begin{array}{l}5 \text { days postoperatively } \\
\text { Gross obesity }\end{array}$ & $\stackrel{20}{20}$ & $\begin{array}{r}110 \\
92\end{array}$ & $\begin{array}{l}120 / 80 \\
120 / 80\end{array}$ & $\begin{array}{l}0 \\
0\end{array}$ & $\begin{array}{l}+ \\
+\end{array}$ & $\begin{array}{l}\text { Normal } \\
\text { Normal }\end{array}$ & $\begin{array}{l}\text { Pleuritic pain } \\
\text { Pleurisy and haemoptysis; leg phlebo- } \\
\text { graphy positive }\end{array}$ \\
\hline $\begin{array}{r}8 \\
9 \\
10 \\
11\end{array}$ & $\begin{array}{l}53 \\
64 \\
54 \\
68\end{array}$ & $\begin{array}{l}M \\
M \\
M \\
M\end{array}$ & $\begin{array}{l}0 \\
0 \\
4 \\
0\end{array}$ & $\begin{array}{l}7 \text { days postoperatively } \\
\text { Carcinoma of ureter } \\
\text { Thrombophlebitis } \\
\text { Previous deep vein } \\
\text { thrombosis }\end{array}$ & $\begin{array}{l}\text { Raised } \\
18 \\
\text { Raised } \\
22\end{array}$ & $\begin{array}{r}98 \\
106 \\
90 \\
120\end{array}$ & $\begin{array}{l}140 / 85 \\
140 / 80 \\
130 / 80 \\
130 / 75\end{array}$ & $\begin{array}{l}0 \\
0 \\
0 \\
0\end{array}$ & \pm & $\begin{array}{l}\text { Normal } \\
\text { Normal } \\
\text { Normal } \\
\text { Normal }\end{array}$ & $\begin{array}{l}\text { Leg phlebography positive } \\
\text { Leg phlebography positive } \\
\text { Leg phlebography positive }\end{array}$ \\
\hline
\end{tabular}

*One pack year $=$ one packet $(20$ cigarettes $)$ a day for a year.

The analysis enables the numerical values derived from the posterior view of each lung scan to be plotted superimposed on the normal range (mean \pm 2 SD) for the subject's age and sex (fig 1). The analysis divides the vertical axis of the ventilation and perfusion scans for each subject into 50 equal intervals, scans each interval for abnormal values, and

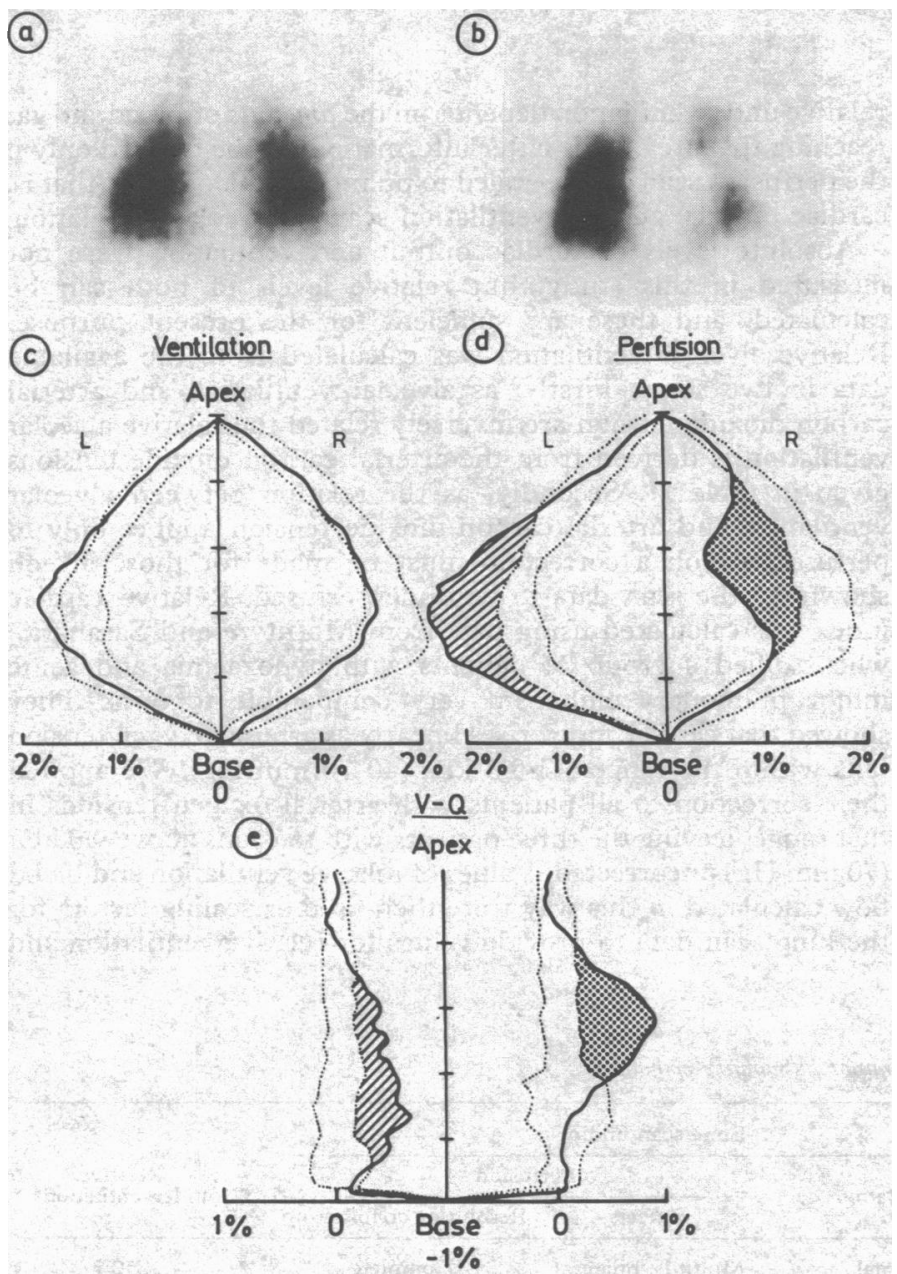

FIG 1-Posterior ventilation (a) and perfusion (b) images (case 10) analysed and presented graphically as ventilation $(c)$, perfusion $(d)$, and ventilation minus perfusion $(e)$. In $c, d$, and $e$ the data are presented as a solid line with normalised lung length on the vertical axis and counts, expressed as a percentage of total counts, on the horizontal axis. The dotted lines indicate the range $( \pm 2 S D)$ in normal subjects matched for age and sex. The stippled areas in $d$ and $e$ are where perfusion counts fall below the normal range (regions of underperfusion and therefore high $V-Q$ ), and the hatched areas are where perfusion counts lie above the normal range (regions of overperfusion and low $\mathrm{V}-\mathrm{Q}$ ). sums low and high values separately. Thus the dotted region of underperfusion in the right lung in fig $1(d)$, for example, is calculated as an area with the units percentage activity $\times$ fractional lung length. The analysis also compares corresponding values of ventilation and perfusion at each interval down each lung, expressing them as a ratio $(\mathrm{V} / \mathrm{Q})$ and as a difference $(\mathrm{V}-\mathrm{Q})$. Both these are variables of ventilationperfusion matching in the lungs. The ratio $V / Q$, though familiar, has a disadvantage for the present study in that it shows very wide scatter at the apices and bases, an effect of taking ratios between two small numbers of counts both of which are subject to statistical variability. In the present study we therefore used $\mathrm{V}-\mathrm{Q}$ as an index of matching, as the normal limits are relatively narrow throughout the lung (fig $1(e)$ ). $\mathrm{V}-\mathrm{Q}$ moves in the same direction as $\mathrm{V} / \mathrm{Q}$ when mismatching occurs; thus low values of $V-Q$ correspond to low values of $V / Q$ and indicate relative underventilation. This type of mismatching (hatched area in fig $1(e)$ ) produces venous admixture and arterial hypoxaemia.

\section{ARTERIAL BLOOD GAS TENSIONS}

Arterial blood was taken during the acute illness, within 24 hours of the lung scan, with the patient breathing room air. Values of $\mathrm{pH}$ and arterial oxygen and carbon dioxide tensions were obtained with a Corning 165 or 168 blood gas analyser. Predicted normal values of arterial oxygen tension were calculated from the data of Sorbini et al. ${ }^{7}$

\section{Results}

Figure 1 shows posterior views of a ventilation-perfusion lung scan in a patient with acute minor pulmonary embolism, together with the computer analysis. The same pattern was seen in all cases, although the extent of the perfusion disturbances varied. All patients showed an area, or areas, of localised underperfusion without an appreciable disturbance of ventilation, which gave an area where the V-Q graph was high (that is, the area of embolism-for example, the right midzone in fig 1). In addition, there were other areas where the perfusion was high and therefore there was relative underventilation (left lower zone in fig $1(d)$, hatched area in fig $1(e)$ ).

Table II gives the arterial blood gas tensions, the nature of the perfusion defects, and the extent of relative underventilation. In all cases the extent of relative underventilation far exceeded the normal limit of 30 units derived from 55 normal subjects.

Figure 2 shows the extent of relative underventilation and the arterial partial pressure of oxygen (measured within 24 hours of the scan) for each patient. The two quantities were strongly correlated $(r=-0 \cdot 68)$

\section{Discussion}

This study presents findings derived from quantitative analysis of ventilation-perfusion lung scans in a series of patients carefully selected to represent acute, uncomplicated minor pulmonary embolism. 
This method of analysing ventilation-perfusion lung scans highlights two main features. Firstly, the region of the embolus is shown as an area where the perfusion graph is below the normal range, ventilation remains normal, and the $\mathrm{V}-\mathrm{Q}$ graph is above the normal range (for example, the right mid-zone in fig 1). Such a pattern is typical of pulmonary embolism. ${ }^{8}{ }^{9}$ The second feature-that of relative overperfusion of those areas not affected by embolism (the left lower zone in fig 1)-is less familiar but occurs because if cardiac output is maintained pulmonary blood flow will be redistributed to regions of lung unaffected by embolism. In acute minor pulmonary embolism uncomplicated by pre-existing cardiovascular or respiratory disease or cardiac failure, cardiac output remains stable or, if the patient has hypoxaemia, rises. ${ }^{1210}$ As none of our patients had hypotension or oliguria and only one had a minor rise in jugular venous pressure, we believe that cardiac output remained normal or was raised in all of them. The perfusion scan, therefore, reflects the redistribution of pulmonary blood flow to non-embolised regions of lung, and as ventilation is not redistributed to these areas mismatching occurs with relative underventilation.

Areas of relative underventilation are a potential cause of hypoxaemia, and the relation shown in figure 2 suggests such a mechanism in our patients. This may be misleading, however, as the lung scan shows only the distribution of blood and inhaled gas, while the severity of the hypoxaemia caused by an area of

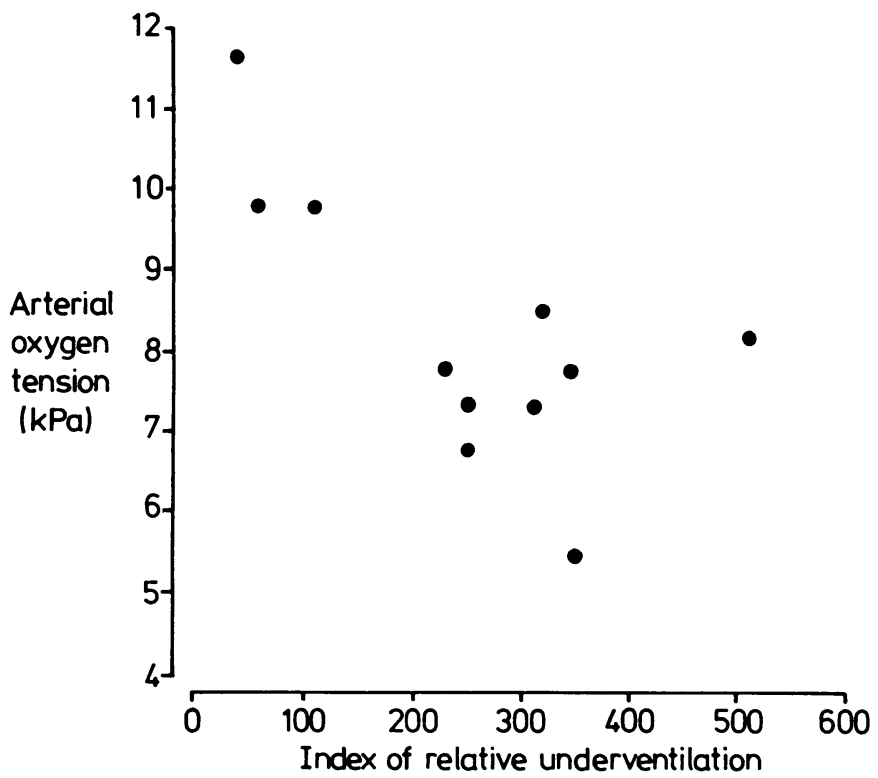

FIG 2-Arterial oxygen tension plotted against index of relative underventilation in 11 patients with acute minor pulmonary embolism. For units of index of underventilation see Patients and methods.

Conversion: SI to traditional units-Arterial oxygen tension: $1 \mathrm{kPa} \approx$ $7.5 \mathrm{~mm} \mathrm{Hg}$.

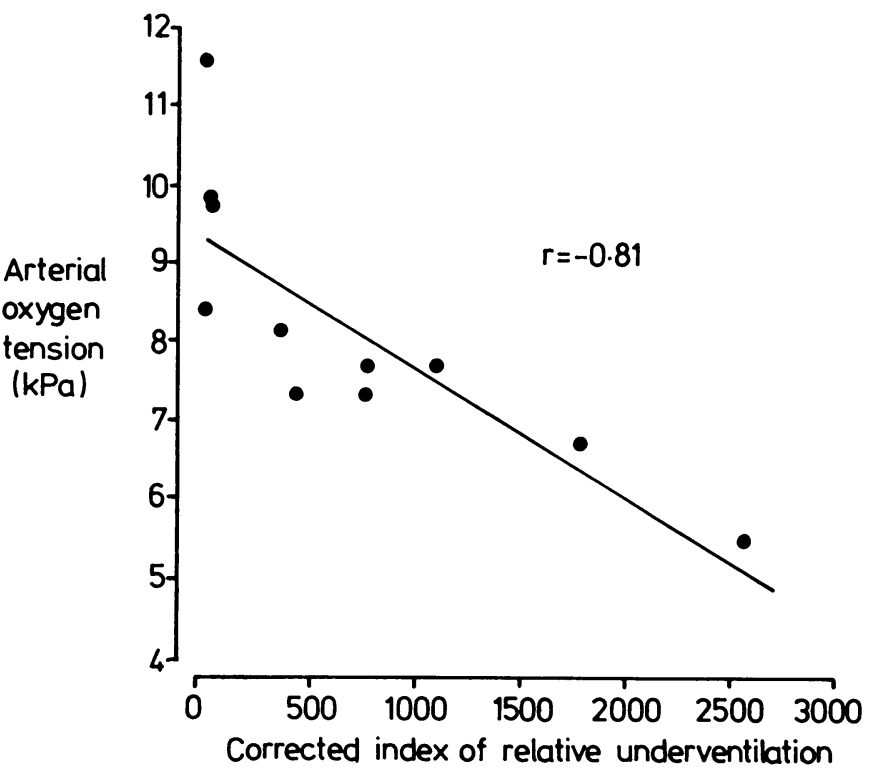

FIG 3-Arterial oxygen tension in 11 patients with acute minor pulmonary embolism plotted against index of relative underventilation calculated to take account of cardiac output and alveolar ventilation as described in the Discussion. Linear regression yielded $y=-0.012 x+69.96 ; r=-0.81, p<0.01$

Conversion: SI to traditional units-Arterial oxygen tension: $1 \mathrm{kPa} \approx$ $7 \cdot 5 \mathrm{~mm} \mathrm{Hg}$.

relative underventilation depends on the amounts of blood and gas reaching that area. This latter information can be derived only if the perfusion scan can be scaled to pulmonary blood flow (that is, cardiac output) and the ventilation scan to alveolar ventilation.

Absolute levels of cardiac output and ventilation were not measured in this study, but relative levels of both can be calculated, and these are sufficient for the present purpose. Relative alveolar ventilation was calculated from the available data in two steps. Firstly, as alveolar ventilation and arterial carbon dioxide tension are inversely related the relative alveolar ventilation is derived from the arterial carbon dioxide tensions given in table II. Secondly, as the relation between alveolar ventilation and arterial carbon dioxide tension applies only to perfused alveoli a correction must be made for those alveoli shown by the scan data to be underperfused. Relative cardiac index was calculated using data from McIntyre and Sasahara, ${ }^{2}$ who studied a group of patients with hypoxaemia and acute minor pulmonary embolism very comparable to ours. They showed that cardiac index rises linearly as arterial oxygen tension falls within the range $5 \cdot 3-9 \cdot 3 \mathrm{kPa}(40-70 \mathrm{~mm} \mathrm{Hg})$. We applied their correction to all patients with arterial oxygen tensions in that range, leaving the three patients with tensions above $9.3 \mathrm{kPa}$ $(70 \mathrm{~mm} \mathrm{Hg})$ uncorrected. Values of relative ventilation and blood flow calculated in this way were then used as scaling factors for the lung scan data to provide values for relative ventilation and

TABLE II-Blood gas tensions and lung scan characteristics of 11 patients with acute minor pulmonary embolism

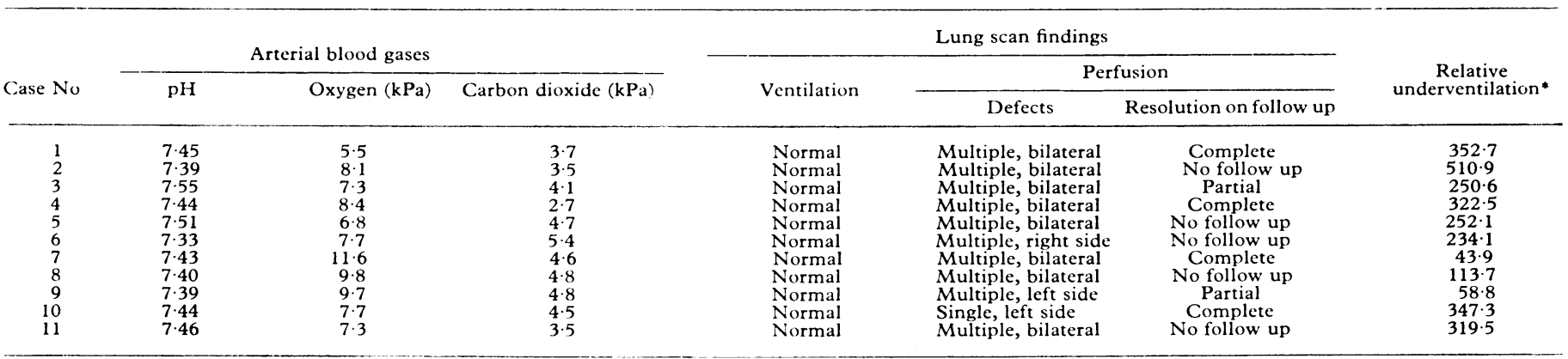

* For units see Patients and methods.

Conversion: SI to traditional units-Blood gas tensions: $1 \mathrm{kPa}=7.5 \mathrm{~mm} \mathrm{Hg}$ 
blood flow in each part of the lungs. From this, values of relative underventilation (summed for both lungs) were calculated and plotted against arterial oxygen tension for each patient (fig 3). The extent of the relative underventilation correlated well with the degree of arterial hypoxaemia. A slight refinement of allowing for the age dependence of normal arterial oxygen tension in calculating the degree of hypoxaemia attributable in each patient to the pulmonary embolism further improved this correlation.

In view of the above considerations we postulate that the development of ventilation-perfusion mismatching in regions of non-embolised lung was an important cause of hypoxaeria in our patients. There has been no general agreement about the cause of hypoxaemia in acute pulmonary embolism in man, and evidence has been provided for right to left intrapulmonary shunting 11 and impairment of gas diffusion. ${ }^{12}$ These results are not necessarily incompatible with ours. Localised atelectasis and prolonged breathing of oxygen may produce shunting. We were at pains to exclude these in the present study, whereas one or more of them appears to have been present in most patients in other studies. " 11 ' 2 Furthermore, other mechanisms of hypoxaemia might be operating in massive pulmonary embolism accompanied by appreciable haemodynamic disturbances, which were not detected in our mild cases.

One possible way of exploring the relative roles of mismatching and shunting would be to use $100 \%$ oxygen breathing as a discriminatory test. ${ }^{13}$ Observations of this kind do not appear to have been reported to date and were not possible in the present series because we studied the patients retrospectively.

Finally, some support for our hypothesis may be drawn from animal studies in which pulmonary embolisation with autologous clot $^{1415}$ or gas bubbles ${ }^{16}$ caused hypoxaemia by disturbing ventilation-perfusion ratios in the direction that we postulate.

GHB was in receipt of a Charing Cross Hospital trustees' clinical research fellowship during part of this work.

\section{References}

' Wilson JE, Pierce AK, Johnson RL, et al. Hypoxaemia in pulmonary embolism, a clinical study. F Clin Invest 1971;50:481-91.

McIntyre KM, Sasahara AA. The hemodynamic response to pulmonary embolism in patients without prior cardiopulmonary disease. Am 7 Cardiol 1971 ;28:288-94. Szucs MM, Brooks HL, Grossman W, et al. Diagnostic sensitivity of laboratory findings in acute pulmonary embolism. Ann Intern Med 1971;74:161-6.

Burton GH, Vernon P, Seed WA. An automated quantitative analysis of ventilationperfusion lung scans. I Nucl Med $1984 ; 25: 564-70$.

ernon P, Burton GH, Seed WA. Quantitation of ventilation and perfusion lung scans. Nuclear Medicine Communications 1982;3:107. perfusion lung scans. Clin Sci 1983;64:49P.

perfusion lung scans. Clin $S c i$ 1983;64:49P.
Sorbini CA, Grassi V, Solinas E, Muiesan G. Arterial oxygen tension in relation to age in healthy subjects. Respiration $1968 ; 25: 3-13$

DeNardo GL, Goodwin DA, Rowasini R, Dietrich PA. The ventilatory lung scan in the diagnosis of pulmonary embolism. $N$ Engl F Med 1970;282:1334-6. Fazio F, Lavender JP, Steiner RE. $\mathrm{Kr}-81 \mathrm{~m}$ ventilation and $\mathrm{Tc}-99 \mathrm{~m}$ perfusion scans in chest disease: comparison with standard radiographs. American fournal of Roentgenology 1978;130:421-8.

"Dalen JE, Banas JS, Brooks HL, Evans GL, Paraskos JA, Dexter L. Resolution rate of acute pulmonary embolism in man. $N$ Engl $f$ Med 1969;280:1194-9.

D'Alonzo GE, Bower JS, DeHart P, Dentzker DR. The mechanisms of abnormal gas exchange in acute massive pulmonary embolism. Am Rev Respir Dis 1983;

Robin ED, Farkner CE, Bromberg PA, Croteau JR, Travis DM. Alveolar ga exchange in clinical pulmonary embolism. $N$ Engl f Med 1960;262:283-7.

entilating parts of the lung. Acta Physiol Scand 1942;suppl 2:1-92.

thromboembolism in dogs. $\mathcal{F}$ Appl Physiol 1975;39:41-6. antzker DR, Wagner PD, Tornabene VW, Alazraki NP, West JB. Gas exchange after pulmonary thromboembolization in dogs. Circ Res 1978;42:92-103.

${ }^{6}$ Verstappen FTJ, Bernards JA, Kreuzer F. Effects of pulmonary gas embolism on circulation and respiration in the dog. Pfluegers Arch 1977;370:71-5.

(Accepted 27 April 1984)

\title{
Persistent fetal haemoglobin and falsely high glycosylated haemoglobin levels
}

\author{
R B PAISEY, R READ， R PALMER， M HARTOG
}

\begin{abstract}
Some of the routine methods of measuring glycosylated haemoglobin depend on its difference in charge from haemoglobin $A$ and do not distinguish between glycosylated haemoglobin and fetal haemoglobin. Two insulin dependent diabetics showed persistent discrepancies between their capillary blood glucose values and their glycosylated haemoglobin values measured by agar gel electrophoresis: the blood values were normal but the glycosylated haemoglobin values were raised. In one patient increases in insulin dose in response to the glycosylated haemoglobin results repeatedly produced hypoglycaemia. Both patients were found to have higher than normal concentrations of fetal haemoglobin; and when measured by the thiobarbituric acid reaction their glycosylated haemoglobin levels were almost normal.
\end{abstract}

This problem may be avoided by using a method that distinguishes between fetal and glycosylated haemoglobin or by testing glycosylation of hair or serum albumin if discrepancies arise. This is particularly important during pregnancy, when some women have an increase in fetal haemoglobin.

\section{Introduction}

Glycosylated haemoglobin is widely used as a measure of diabetic control in insulin treated patients, often in conjunction with home blood glucose monitoring. Some of the methods routinely used for measuring glycosylated haemoglobin depend on its separation from haemoglobin A by a difference in charge-for example, column techniques and agar gel electrophoresis. With all of these methods fetal haemoglobin $(\mathrm{HbF})$ will migrate with glycosylated haemoglobin and, if present, give a falsely high reading.'

\section{Case 1}

A 24 year old research assistant had been diabetic for 15 years. She adjusted her dose of twice daily quick and intermediate acting insulins according to home blood glucose concentrations measured by BM $20-800$ strips and confirmed by filter paper capillary blood glucose measurement. These consistently showed normal or near 